\title{
Risk and Society: Implications for Insurers
}

\author{
by Brian Corby*
}

You will have read in the introduction that in some way I'm held responsible. Clearly, if nothing else, it shows ths risk involved in making a throwaway remark.

Be that as it may, I was at the time concerned at the developing conflicts of attitude in society against which we as insurers have to operate. These conflicts appear at present to be becoming more pronounced.

In particular, I was concerned at the pressures which arise from a number of factors.

First, we have the pressure - general in most western economies - for more competition, and especially for more competition in the provision of services.

Then we are conscious that we are operating in an environment in which the individual appears to be increasingly risk averse and looks for protection from all ills irrespective of the extent to which he personally might be responsible.

Thirdly, and associated with the second point but not quite the same, we have strong pressures from consumers - and perhaps more correctly from those who purport to be acting on behalf of consumers - for more protection for consumers.

It is easy to see that the pressure for more competition is in conflict with risk aversion and in the ultimate with consumer protection. It is equally obvious that one result will be to increase the cost of services and, more seriously, if we do not get the balance right, will lead to a service not being available.

I am concerned with the interface between our business and society and I would like to deal with this theme first in general terms and then, because it is always easier to discuss specific issues, to relate it to what are a few of the current topics with which we as insurers are concerned.

* Chief Executive, Prudential Corporation plc, London. 
The first point to make is that this subject is clearly of concern in most countries in which insurers operate. This is borne out by those of you here. It is of interest too that the Bayerische Ruck, to celebrate their 75th Anniversary, have produced a collection of essays on the subject of "Society and Uncertainty", which I would recommend to those who have not yet had the opportunity of reading it, although it is perhaps less specific in relation to insurance than our conference today. I am grateful to the compilers of that book for drawing to my attention what seems to be a very apt quotation from Hayek's "The Road to Serfdom" - "Some security is essential if freedom is to be preserved, because most men are willing to bear the risks which freedom inevitably involves only so long as that risk is not too great."

Insurance is, of course, one of the ways which society has adopted to give this security. There are others, such as the limited liability concept. And, in the ultimate, the state as protector againgst all vicissitudes of life but I suspect if you get to that point you've gone back to serfdom.

Progress in society will almost always involve added risks which society may not tolerate. Where an industry supplies physical products competition involves introducing better products and/or cutting costs and prices. Excessive competition may of course result in firms going bankrupt but can at the same time benefit the consumer. Or it can have the effect of so reducing the quality of goods that they no longer function effectively or, far worse, safety standards fall below the acceptable level.

In insurance we are dealing in promises rather than products and competition could so easily lead to promising more than one can deliver. It is not unreasonable therefore that we have the approach to regulation that we have. It may be worth reminding ourselves that the original reason for insurance premiums being subject to regulatory control in the USA was not to protect the consumer from an industry that might establish a cartel - or tariff - to overcharge, but rather to ensure that under the pressure of competition rates did not fall to such a level as to prejudice solvency. Clearly we had here regulation which sought to reduce the risk of insolvency and which at the same time was anti-competitive, since price is one of the most important elements in competition.

As I have already mentioned, there is evidence that the attitude of society to risk is changing. As with all changes of attitude the position is not entirely clear, but there appears to be a strong thrust towards an attempt to reduce the level of risk to which individuals are subjected.

There could be a number of reasons for this; for example, developments which either do or are perceived materially to increase the level of risk, coupled with a population which is better educated and better informed. There may be, at the same time, a growing sense of remoteness from those who take decisions which affect the level of risk, or it may be that a more fundamental shift is occuring; society in some absolute sense may be becoming more risk averse which may be the consequence of having more to lose.

I readily accept that individuals have for long shown themselves to be risk averse in the sense that - for example with a motor insurance policy - they have been prepared to pay 
premiums which are greater than the expected return (I'm assuming the insurer makes a profit!).

Of special relevance at this time in the United Kingdom is the development in consumer and investor protection under the Financial Services Act. It is no cause for surprise that at the same time as the financial services sector is being encouraged to be more competitive we are introducing measures designed particularly to protect the consumer, the investor or the insured. As the debate over the last few years has progressed, and as the current proposals are implemented, it is interesting that the thrust has been to strengthen the controls and regulations, often at the behest of practitioners. It is almost as if they were concerned at the consequences of the other changes currently taking place or, if one were cynical, they were worried what their competitors might do!

That we have conflict is obvious. It is I think equally obvious that it would be extremely foolish to believe that this conflict can be resolved in any absolute sense, that there is in fact a unique solution for which we must strive. What we should aim for is an understanding and a preparedness to recognise the dilemma. Ideally we would seek recognition on the part of everyone, but such recognition is most important at the political level, since otherwise those who find themselves in the position of regulators could so easily find their position untenable.

It is at this point that our individual perceptions of risk become so important. At a very simplistic level we all know that if we are driving along a motorway and we see a particularly horrific accident we tend to slow down, at least for a mile or two. But as far as we are concerned, the risk of accident is not changed unless the accident itself makes us aware of conditions not previously known to us. Our behaviour may well be quite irrational.

Returning to the investor, we can I think all agree that those who invest in a particular way - say in an insurance policy, a unit trust or directly on the stock exchange - may not do as well as they expect, but when it happens to you personally there may well be a tendency to say that it should not have happened and that the rules should be changed. Even the most liberal of us, or even the most conservative of voter - they are not necessarily mutually exclusive - can be heard to say "the Government ought to do something about it" when faced with an event which they don't like.

What is as certain in the future as it is in the present and has been in the past is that disappointments and failures will occur. This would apply even if all practitioners in the market were of the utmost probity and competence. And I have no reason to believe we shall achieve that position. It is for this self same reason that it is important that we achieve a full recognition of the dilemma which I have outlined, so that when the disappointment or failure does occur we do not automatically say - as so many may say - that the system itself must be changed. It may be that it is precisely the opposite and that the system has worked and has worked well.

To summarise, "there is the danger of getting into a spiral of measures designed to increase the competitive nature of our society which we then counter with measures to miti- 
gate the effect. The end result of such a process could all too easily be one of screwing-up the whole system."

I have used the word "risk" so far without being precise as to its meaning. Discussions have taken place at the academic level as to whether pure risk can be connected only with loss and not with success. The Royal Society set up a study group on risk in 1978 which reported in 1983. They had problems in definition but finally settled on "Risk as the probability that a particular adverse event occurs during a stated period of time or results from a particular challenge" where "an adverse event is an occurence that is producing harm". The association with adversity is clear. That the report took so long to prepare is explained as reflecting the different approaches of the academic disciplines involved in areas such as engineering and biological risk.

In relation to attitudes to risk, one conclusion is very relevant to our topic - "scientific determinism has replaced religion and magic as the way in which many ordinary people explain adversities and one consequence is that there is generally a search of causes and an attribution of responsibility or blame."

If we accept that position, it is not perhaps unreasonable for people to look for scapegoats and to endeavour to exact retribution when someting goes wrong. To see how this can affect our business we don't need to look further than the US with its tort system and contingency fee lawyers.

The Royal Society's study concludes that "at the more strategic levels risk management is an essentially political process informed by technical estimates" leading to recommendation for the "involvement of the public and their representatives and of specialists in discussion and in the regulatory process with the aim of achieving a more balanced approach to the inevitable existence of risks and detriments".

When he gave the Richard Dimbleby Lecture in 1978, Lord Rothschild chose "Risk" as his subject. In relation to the extracts I have just quoted, it is interesting that he remarked that he was not too happy about leaving the treatment of risk to the judgment of politicians. Maybe I am not too happy either, but I have to confess I can't think quite where else to leave it.

Much of Lord Rothschild's lecture was devoted to quantification of levels of risk and their acceptability. Obviously it is appropriate for society to endeavour to make assessments on such a basis. Equally it is obvious that for the individual the consideration is quite different. To what extent are an individual's decisions on activity - perhaps sporting activity determined by a rational calculation of risk? It is simple to tell a group of men all of the same age what proportion can be expected to survive a year, but the individual's interest is whether he is alive or dead at the end of that time. Even an actuary can't tell him that.

It may be quite rational to say that the insurance regulatory system should aim to secure that no more than one insurance company should have financial difficulties in " $N$ " insurance company years - and I am not going to speculate on what "N" should be. However, what is of concern is what action is taken when the difficulty occurs. It is hardly 
surprising that it has proved difficult to reconcile a probabilistic approach to this problem with those who, equally correctly, ask that sufficient free reserves should be held in the case of an adverse event occurring quite independently of the probability of that event.

I have already referred to the fact that individual attitudes to risk will often be irrational. A paper in a series of reports prepared in Sweden as part of a project on "Risk generation and Risk assessment in the Social Perspective" covering ground similar to that of the Royal Society's study I have previously mentioned, commented that between $75 \%$ and $90 \%$ of car drivers at any time consider themselves to be driving better than the average driver. Now I doubt whether this is a quality unique to Sweden and it appears to lack credibility, whilst at the same time illustrating clearly the subjectivity of the individual assessment. We must surely expect such subjectivity to be applied in other areas - not least political areas where probabilistic assessment is what is really required.

The other aspect I would mention here is in relation to the aggregation of risk. Public behaviour and response is affected by the size of the adverse event, whatever the probability assessment may be. A single disaster affecting a large number of lives is far more likely to lead to political action than, say, the death of a far larger number in individual or near individual incidents. Perhaps it should be so - I make no judgment - but what is relevant here is that when we draw up the rules - when we try to achieve an acceptable balance - we take this factor into account.

It is interesting in this respect to compare attitudes to Bhopal - no-one suggested we stop chemical plants - and those to Chernobyl, the potential horror of which led many to call for a re-think of policy on power.

All human activity involves risk. Man's knowledge of his environment, more recently extra-terrestrial, did not come about by avoiding risk, nor did the great political, scientific or industrial developments that enable us to live as we do today. At the everyday level, we take risks constantly as we take choices in our private or in our business lives. Most of the risks are of the utmost triviality, which is fortunate because I am sure we couldn't otherwise take the strain.

But other risks are substantial. For example, a business choosing to adopt a new process or to develop a new plant and, with the size of businesses, these decisions are becoming more important and more risky all the time. And society has sought to make these risks acceptable for example by spreading the risks through limited liability or by exchange through insurance. Note that this is making the risk acceptable or alleviating the effect of the risk. It is not an attempt to get rid of the risk, although damage limitation it may be. No amount of life assurance will prevent you dying, indeed too much might tempt someone to accelerate the process, although it may make your departure more bearable for your dependants.

I mentioned that there was a danger that the twin increasing spirals of more competition and more protection by more regulation might cause the system to seize up. There is another aspect of this which is very concerning and where the results are already being seen. This is that the process of protecting the consumer, in particular that of giving him excessive 
support when the supply of services or of manufactured goods goes wrong, can so easily lead to those services or goods not being made available. The results of this are all too evident in the United States. And it could easily happen elsewhere. I know that the question of balance is not a very exciting topic but if you get the balance wrong, or more particularly if you allow or encourage a balance which has evolved over many years to change too quickly, you will also risk causing a breakdown of the system.

I have referred earlier to the implications of these attitudes in a favourable (?) legal environment.

Some remarks by a former chairman of Citicorp to a meeting in New York are relevant - "Innovative lawyers working for large contingency fees developed discovery procedures that are out of control. They have ascribed to health care procedures long term effects that were totally unknown at the time of treatment and have attempted to embed in the law the concept that risks should be removed from life." Which should make us all stop to think as he concluded "all of this excess of a litigious society is driving the insurance business out of business."

As long ago as 1978 one writer in the "Geneva Papers on Risk and Insurance" likened the situation to what has been called the "tragedy of the commons" whereby increases in the number of grazing sheep by some led to increases by others with inevitable over-grazing and destruction of the common land for all.

To the extent the insurance industry has had problems, it must accept a major share of the blame itself. Surplus of capacity was undoubtedly one factor, but so too was competition from other industries, notably the banks. There are clear instances of failure to differentiate between what were properly entrepreneurial risks and what were really appropriate for insurance. This meant that under the pressure of competition insurers were tempted to go into fields for which they were ill-prepared. And with inevitable consequences.

In a very real sense our industry suffered because we forgot - or deliberately overlooked - the fundamentals of our business. For example whilst a reasonable spread of risk may be highly desirable it is not essential. What is essential is that the insured as well as the insurer should be interested in not having a claim - we must never overlook the moral hazard.

Perhaps I could conclude this general section of my remarks by referring again to how important it is to get across an understanding of the dilemma between risk aversion and the need for more competition. In the 6th Annual Lecture to the Geneva Association given in 1982, Professor Raymond Barre posed the following question - "We are living in a world where uncertainty is growing and risks are becoming ever more extensive. At the same time we note an upward trend in the demand for security. To what extent can the demand for security be met by the state without slowing down or hindering the adaptions made necessary and inevitable by the far reaching changes in the world?" And he went on to say that in the final analysis this question concerns a choice of society.

As I have already said, this is clearly a political question. 
I am sure that nobody - or at least no insurers - would argue against the proposition that insurance involves underwriting and selection. Indeed, if it is possible for an insured, or rather potential insured, to select against the insurer then to protect himself the insurer must be able to decide whether or not to accept a risk and, if so, on what terms.

Let us relate this to life insurance. Reference to "Risk Appraisal" by Harry Dingman 1957 edition shows that in the older friendly societies, guilds and lodges "young and old, hale and frail, all paid alike." But he goes on - under the heading "Groping" - perhaps that is a way of describing a medical exam! - and I quote "Age and health standards were prescribed by the Society of Assurance for Widows and Orphans in 1699, and by Amicable Society for a Perpetual Assurance, 1706, inaugurating a systematic groping for basic guides of appraisal. Amicable set age limits of 12-45, and required applicants to appear before the Court of Directors.'

London Assurance, 1725, delegated underwriting responsibility to at least one agent, a Mr. Porter of Dublin, enjoining him that applicants must appear before him for questioning into health and manner of life, with supplementary inquiries to be made of their neighbours. "You are to learn, if possible, the reason why the assurance is made, for unless there are good reasons ... the person assured may be in a worse state of health than you apprehend." Passage to England added half a guinea to the cost, presumably because of the journey not the destination. Travel elsewhere in the world voided the contract unless special deal was made with the Court of Directors.

Reference to the history of the Equitable by Maurice Ogborn gives the following information - "The applicant for life assurance had to come to the Society's house on a Tuesday, at an appointed time from 11 o'clock onwards, when the Court of Directors was in session. The applicant was met in the outer room of the office by the actuary or one of his assistants who required him to sign a declaration in a printed book of forms. This gave his name, address, occupation and age and information about his state of health. If the assurance was to be on the life of another person, a longer declaration had to be made, setting out the nature of the insurable interest, and the deeds establishing the interest had to be produced.

The applicant was next shown into the Court room, where the directors were meeting, and it may be guessed, took a place reserved for him at the table. The chairman asked the actuary to read the declaration just made by the applicant and the directors doubtless took the opportunity to question the applicant about the assurance and his state of health, after which he was requested to withdraw while the court gave due deliberation 'to the proposal to assure the life'."

This was in 1762 .

Thus from the earliest days of life assurance on a scientific basis we have the concept of selection on grounds of health and in about 1776 the Equitable appointed a doctor for this purpose. 
In a sense, these extracts that I have quoted are for interest only, but they do show quite clearly that our business is based from its beginnings on an assessment of the risk - on selection.

But an alternative word for selection is discrimination and discrimination has now taken on a pejorative meaning. I can only say that if selection means discrimination then as an insurer I must insist on the ability to discriminate and we have no reason whatsoever to apologise for that.

Clearly the most sensitive areas in this respect at present are gender and AIDS.

For so long as we are in a position to be selected against - discriminated against - I do not see any way that we can operate otherwise. And this must be on grounds both of equity and of solvency. Even when a company has a monopoly - for example the monopoly of life insurance in India - underwriting, and therefore selection, will continue to be practised.

I well recognise that in taking this view we as insurers will appear to set ourselves against powerful groups in society. For example, in Bests for July this year Mr. Hiam, the Massachusetts Insurance Commissioner, said that unisex rating for all lines will probably be effective July 1, 1988, on a prospective basis for new and renewal business. "Society makes up its mind - not the insurance industry - what factors are appropriate to use in underwriting", the commissioner said, and there is much support in the Bay State for the idea that gender should not be a rating factor.

Now setting aside any thoughts we might have as to how views like that could be put forward in a society that is supposed (I use that word advisedly) to encourage free enterprise and competition, can it seriously be suggested that that is a sensible way to run any insurance business with a commercial basis?

This is not a matter of bias, whatever the lobbyists may say. This is a simple recognition that sex is a factor in mortality and morbidity rates and failure to recognise that fact enables a potential insured to select against the insurer. Perhaps the differences that so clearly exist should not exist, but as long as they do we have to have regard to the levels of risk as we see them.

Perhaps I could move from here to the more topical and far more sensitive subject of AIDS. Again a quote from Bests - "Another problem continuing to face life insurers this year is AIDS. Massachusetts Insurance Commissioner Peter Hiam, who has forbidden the use of AIDS antibody testing as part of insurance applications, told the meeting that the life insurance industry has shown no financial need that would override the public interest of avoiding the stigmatization caused by positive or false positive AIDS test results. Intravenous drug abusers are the fastest-growing group of AIDS patients in Massachusetts, he said, but he added that he didn't think they are a group likely to purchase a lot of insurance."

The final remark in what $\mathrm{I}$ have quoted must be regarded as laughable by those who have seen advice being given to the effect that those who might risk declinature should 
effect a large number of policies of such a small size that their condition would not be detected.

Don Barnes writing in the National Underwriter August 17, 1987 quoted Don Ross, chairman of New York Life, as saying "A year ago, based on reasonable assumptions, we determined that if we did not combat anti-selection by AIDS carriers and did not raise our premium, New York Life would probably face insolvency within a decade".

Reference to insolvency may be extreme, I just don't know, but clearly it is a risk and a risk more serious than inequity between different policy-holders, unless we are permitted to underwrite - to select - yes to discriminate - the lives who propose to us for insurance. Dreadful disease as it undoubtedly is, we have to be able to underwrite for it as we do for any other disease and we have to do it as sensitively as we can. And the questions we ask have to be sufficient to identify selection against us.

We must not overlook that we have a voluntary market in insurance. Nor that on the information currently available the mortality rates associated with identified AIDS victims are so much higher than those who have medical impairment but whom we are prepared to accept on special terms, as to be a matter of principle rather than of degree.

On the positive side the industry can take credit for developments which have meant that diseases which some years ago would have led to a life being declined, can now be handled by special terms.

Obviously we shall be faced with a powerful lobby on this, our response must be by way of education and information and by stressing that any changes in our approach to the risks involved must be detrimental to the majority of our customers.

Turning to general insurance, one topical area in the United Kingdom in which we as insurers face problems vis-à-vis society's perception of its needs, is in relation to the provision of insurance cover for businesses, particularly small businesses, in inner cities. The background is one of economic decay and rising crime. Failure of insurers to keep premiums rising in line with claims over a period meant serious losses and as the situation was recognised, serious increases in premiums and a decline to renew. It was not surprising that we faced an outcry both on grounds of affordability of insurance, but also of availability.

As an industry we had no reason to be surprised by the developments since a ready analogy exists with US experience.

Insurers operate with a view to the making of a profit from the provision of insurance services. The level of profit, over any sensible period, must be adequate having regard to the capital and resources deployed. There is clearly distribution of resources between policyholders because that is the nature of the insurance mechanism, and we endeavour to make this redistribution "fair" by charging the appropriate premium, by underwriting.

We have to be very wary of going beyond the redistribution which is fundamental to insurance to redistribution for some other purpose which can only have the effect of subsi- 
dising one group of policyholders at the expense of another. Thus we should try very hard to deal with problems such as those of inner cities on a commercial basis, on the basis of underwriting the risk that we find. I know that this may not be sufficient and principles may have to be modified, I hope only over a short period. But our aim must be - and is - to provide cover on mutually acceptable terms associated with advice on security and risk reduction.

Obviously in areas such as this moral hazard is a relatively large factor in assessing a risk which points to the need for meaningful levels of coinsurance with the insured.

It must be accepted, however unwilling we may be to admit it, that there will be occasions when we compromise our principles in accepting the requirement of society, to a large extent as a "price" for our staying in business. Probably the most obvious example of this is in "Policyholder Protection" legislation. In this country even policyholders of a failed insurer are protected at the expense of the industry as a whole. Now clearly it is not an attractive proposition to be required to support policies of a failed company which could well have been under-cutting you in competition. But the alternative might have been increased capital requirements or more stringent regulation and the industry accepted the legislation as a reasonable compromise.

Finally I would like to turn to a consideration of environmental/pollution risks which illustrate a different sort of interface between insurance and society, in part at least associated with the potential size of such claims. I've already mentioned Bhopal and Chernobyl, but none of you will be unaware of the possible size of some of the liabilities which the insurance industry faces under this head.

The search for a scapegoat - for someone who can be held responsible when something goes wrong - leads naturally to the hypothesis that the polluter will be held responsible and will be required to pay. This implies firstly that he will take more care and, secondly, in his own interests he will seek insurance. That such insurance should not reduce the extent of the care is obvious, the comity of interest between insured and insurer is clear and close cooperation is vital.

At the other extreme the state - or society as a whole - can pick up the burden. This implies that the polluter if left to his own devices will tend to take less care. And when something for which society is paying occurs, society will also be likely to exact retribution in some way.

To my mind a society which operates in the first way is more likely to progress than one that operates on the second, which would lead to more and more control by the state over economic activity.

However, the first course will only work if society accepts that there are sensible limits which must be applied to the liability of the polluter. If not, the end result will also be a stifling of entrepreneurial activity with all that means in terms of human progress. 
I have been reported as expressing the view that insurance as an industry was insufficiently regarded in our society. At the time I had very much in mind our industry's general contribution to the economic life of this country and, in particular, its contribution to the balance of payments. But its importance goes beyond that in that it is fundamental to the way society operates: without sufficient security our system would not work. This applies to the individual as much as to the large corporate entity. It is for these reasons that $I$ have supported the work of the Geneva Association. ing?

What can we as insurers do to improve our position, to bring about more understand-

First we must look to ourselves and the way we carry out our business. There are certain fundamentals which must not be forgotten under pressure of competition and pressure for more innovation. Moral hazard is still of paramount importance, the insured must want to make a claim. The degree of uncertainty attaching to certain events may be such as to render them uninsurable and we have to avoid the blandishments which would have us act otherwise. And some risks may be so great that we ought either to seek their limitation or the involvement of the state.

Second, although I have not so far touched on it, we have to take a positive attitude to risk management and mitigation. To me it is an integral part of our business.

Lastly, we must work far harder than we have so far at informing and educating society at all levels of the importance of our industry and how it is connected with and contributes to virtually every aspect of economic life. 